\title{
Prevalência e fatores associados à violência no ambiente de trabalho em agentes de segurança penitenciária do sexo feminino no Brasil
}

\author{
Prevalence and violence-associated factors \\ in the work environment of female prison guards in Brazil
}

\author{
Marcelo José Monteiro Ferreira ${ }^{1}$ \\ Raimunda Hermelinda Maia Macena ${ }^{2}$ \\ Rosa Maria Salani Mota ${ }^{3}$ \\ Roberto da Justa Pires Neto ${ }^{4}$ \\ Ageo Mário Cândido da Silva ${ }^{5}$ \\ Luiza Jane Eyre Sousa Vieira ${ }^{6}$ \\ Bernard Carl Kendall ${ }^{7}$ \\ Ligia Regina Franco Sansigolo Kerr ${ }^{1}$
}

\footnotetext{
${ }^{1}$ Programa de PósGraduação em Saúde Coletiva, Faculdade de Medicina, Universidade Federal do Ceará (UFCE). R. Professor Costa Mendes 1608, Rodolfo Teófilo. 60430-140 Fortaleza CE Brasil.

marceloferreira@ufc.br ${ }^{2}$ Departamento de Fisioterapia. Faculdade de Medicina, UFCE. Fortaleza CE Brasil.

${ }^{3}$ Departamento de Matemática, UFCE. Fortaleza CE Brasil. ${ }^{4}$ Departamento de Saúde Comunitária, Faculdade de Medicina, UFCE. Fortaleza CE Brasil.

${ }^{5}$ Programa de PósGraduação em Saúde Coletiva, Universidade Federal do Mato Grosso. Cuiabá MT Brasil.

${ }^{6}$ Programa de PósGraduação em Saúde Coletiva, Universidade de Fortaleza. Fortaleza CE Brasil.

${ }^{7}$ Tulane of Public Health and Tropical Medicine, Department of Global Community Health and Behavioral Sciences. Nova Orleans Luisiana EUA.
}

Abstract This article aims to estimate the prevalence and violence-associated factors in the work environment of female correctional officers in Brazil. A cross-sectional, analytical study was conducted in 15 female correctional facilities in Brazil's five regions. Pearson's chi-square test was performed. The Odds Ratio and Confidence Intervals were estimated for factors that showed a significant association or were confounding factors. The prevalence of having experienced at least one violent occurrence during professional duty as an officer was $28.4 \%$. An interesting factor is fact that agents themselves are identified as the main suspects of robbery (74.6\%), moral violence (68.1\%) and sexual harassment (66.8\%) against their co-workers. Working in more than one correctional facility increased the chance of suffering from violence $(O R=3.23$; $C I=1.51-6.9)$. The main associated factors are: working in temporary detention centers, age of admission to the prison system and low social support among co-workers. Violence in the Brazilian prison environment is of great magnitude and considered a complex phenomenon with multiple causes. To combat this, it is necessary to adopt intersectoral actions, capable of intervening both in the prison environment and in society.

Key words Workplace violence, Penitentiary officer, Aggression, Public security, Occupational Stress
Resumo O objetivo deste artigo é estimar a prevalência e os fatores associados à violência no trabalho em agentes de segurança penitenciária do sexo feminino no Brasil. Estudo seccional, analítico, de abrangência nacional, realizado em 15 unidades prisionais femininas nas cinco regiões do Brasil. Foi realizado o teste de qui-quadrado de Pearson. O Odds Ratio e os Intervalos de Confiança foram estimados para os fatores que apresentaram associação significativa ou mostraram-se como fatores de confundimento. A prevalência de pelo menos um episódio de violência foi de 28,4\%. Chama a atenção o fato das próprias agentes serem apontadas como as principais suspeitas de praticarem roubos $(74,6 \%)$, violência moral $(68,1 \%)$ e assédio sexual $(66,8 \%)$ contra as colegas de trabalho. Trabalhar em mais de uma unidade prisional aumentou a chance de sofrer violência $(O R=3,23$; $I C=1,51-6,9)$. Os principais fatores associados são: trabalhar em casas de privação provisória, idade de ingresso no sistema prisional e baixo suporte social entre colegas de trabalho. A violência no ambiente prisional brasileiro é um fenômeno complexo e multicausal. Para o seu enfrentamento é necessária à adoção de ações intersetoriais, capazes de intervir tanto no ambiente prisional como na sociedade.

Palavras-chave Violência laboral, Agente de segurança penitenciário, Agressão, Segurança pública, Estresse ocupacional 


\section{Introdução}

A violência é considerada um dos grandes problemas sociais e de saúde na atualidade. De acordo com o Relatório Mundial sobre Violência e Saúde, registram-se anualmente mais de 1,3 milhões de mortes no mundo em consequência da violência, em todas as suas manifestações ${ }^{1}$.

A violência no ambiente de trabalho também é considerada um importante problema de saúde pública. Para o Joint Programme on Workplace Violence, a violência no trabalho é definida como qualquer incidente onde trabalhadores são abusados, ameaçados ou agredidos em circunstâncias relacionadas ao ofício que desempenham. Esses eventos podem assumir a forma de abusos ou agressões de natureza física, moral ou psicológica, desencadeados tanto por colegas de profissão, como por empregadores, clientes, pacientes ou acompanhantes ${ }^{2}$.

A violência no trabalho é um fenômeno comum, porém, muitas vezes não notificado em diversos países. Apesar disto, o Crime Survey for England and Wales estimou que, durante os anos de 2011 e 2012, cerca de 1,4\% dos trabalhadores adultos foram vítimas de um ou mais incidentes de violência no trabalho. Outros $0,7 \%$ informaram que foram agredidos fisicamente e $0,8 \%$ ameaçados enquanto estavam trabalhando. Isso representa cerca de 312.000 vítimas de violência, 159.000 agressões e 169.000 ameaças nesse período ${ }^{3}$.

A ocorrência de violência no trabalho é mais frequente em algumas ocupações, tais como profissionais de Saúde, Educação e Agentes de Segurança Penitenciária (ASP). As particularidades inerentes a essas categorias profissionais contribuem para que os trabalhadores estejam mais expostos a esses eventos ${ }^{4}$.

No caso dos ASP, o contato direto com a população privada de liberdade, superlotações, rebeliões e o baixo efetivo de profissionais em relação à população encarcerada figuram entre as principais causas para a ocorrência de agressões $\mathrm{e}$ ameaças no ambiente prisional ${ }^{4}$. Somam-se, ainda, a diversidade de funções exercidas pelos ASP no âmbito do sistema penitenciário, tais como ressocializar, vigiar e disciplinar os indivíduos em privação de liberdade 5 .

Além disso, os ASP utilizam-se, muitas vezes, de práticas agressivas no seu cotidiano laboral. A punição sobre as populações encarceradas torna-se um instrumento de coerção, empregada como um dispositivo para o disciplinamento dos detentos. Por outro lado, os ASP também são vítimas de violências, perpetradas tanto por colegas de trabalho como por detentos no ambiente prisional ${ }^{6}$.

A violência física e a violência psicológica interferem negativamente nas condições de saúde dos ASP, comprometendo o seu processo de trabalho. Pesquisa realizada entre ASP norte-americanos durante os anos de 1999 a 2008 registrou uma prevalência de 3,0\% de agressões não fatais, o que corresponde a 125.200 eventos ao ano ${ }^{7}$.

O National Institute for Occupational Safety and Health nos Estados Unidos demonstrou que no ano de 2011, foram notificadas 4 vezes mais doenças relacionadas ao trabalho entre ASP quando comparados com as demais categorias profissionais no país. Em relação aos acidentes de trabalho decorrentes de agressões, esse número foi 36 vezes superior entre os ASP do que o encontrado para o restante da população trabalhadora norte-americana ${ }^{8}$.

Somente no ano de 2013, o French National Observatory of Crime registrou uma prevalência de $9 \%$ de violência física contra ASP, pouco mais de 4 vezes superior ao estimado para a população trabalhadora francesa em geral ${ }^{9}$. No Canadá, foram identificadas associações positivas entre a tensão no trabalho, o baixo suporte social dos colegas/supervisores e o assédio moral no traba1 ho ${ }^{10}$. ASP italianos apresentaram exaustão emocional relacionada à exposição a situações estressantes como censuras injustas, trabalho extra e exposição a insultos/ameaças dos detentos ${ }^{11}$.

Violências, agressões e ameaças são consideradas como os principais fatores de risco para o desenvolvimento de problemas de saúde entre ASP. Além disso, o trabalho desses profissionais é extremamente estressante, podendo trazer consequências graves para a sua integridade física e psicológica, tais como ansiedade e estresse ${ }^{12}$.

Pesquisas relacionadas à violência no ambiente de trabalho dos ASP estão descritas na literatura mundial ${ }^{3,5,7-12}$. Contudo, ainda persistem grandes lacunas quando se trata especificamente da população de ASP do sexo feminino. No Brasil, apesar de possuir a 3a maior população carcerária do mundo, esses estudos também são escassos. O presente manuscrito objetiva estimar a prevalência de violência no trabalho e seus fatores associados em Agentes de Segurança Penitenciária do sexo feminino no Brasil. 


\section{Materiais e métodos}

\section{Tipo e local de estudo}

Foi realizado um estudo seccional, analítico, de abrangência nacional em 15 unidades prisionais femininas localizadas nos estados do Pará e Rondônia (Região Norte), Ceará (Região Nordeste), Distrito Federal e Mato Grosso (Região Centro-Oeste), São Paulo e Minas Gerais (Região Sudeste), Paraná e Rio Grande do Sul (Região Sul). O estudo foi realizado no período entre janeiro de 2014 a dezembro de 2015, como parte do projeto intitulado Inquérito nacional de saúde na população penitenciária feminina e de servidoras prisionais.

\section{População de estudo e amostra}

A população consistiu em ASP do sexo feminino, vinculadas formalmente ao sistema penitenciário brasileiro, atuando em contato direto com mulheres privadas de liberdade e que aceitaram participar do estudo. Devido à ausência de informações oficiais sobre a população de estudo no Brasil à época da realização da pesquisa, o plano amostral levou em consideração a população carcerária feminina, sendo realizada em múltiplos estágios.

Inicialmente, foram selecionados, intencionalmente, dois estados por região político-administrativa brasileira que tinham as maiores populações carcerárias femininas ${ }^{13}$. Em seguida, os presídios foram estratificados de acordo com a localização (capital, região metropolitana ou interior). Foram incluídos na amostra apenas os presídios com mais de 75 detentas, devido à obrigatoriedade de possuírem serviços de saúde e pela infraestrutura não se assemelhar às de delegacias ${ }^{14}$.

A amostra foi estipulada em $40 \%$ das ASP presentes no momento da coleta. Em unidades prisionais onde o quantitativo de ASP era igual ou inferior a 33 profissionais, a totalidade das agentes foi incluída. Foram excluídas do cálculo amostral as ASP em férias, afastamentos, licenças ou recém-ingressas com menos de 30 dias no sistema prisional.

A população de estudo nas unidades prisionais durante a coleta foi de 810 ASP, sendo estimada uma amostra de 324 agentes de todos os turnos e equipes de trabalho. Destas, ocorreram 4,6\% de perdas na seleção inicial devido à escolta externa e acompanhamento das detentas aos serviços de saúde. Ao final, foram abordadas 371 ASP, tendo ocorrido 20,5\% de desistência e/ ou recusa, perfazendo uma amostra final de 295 participantes.

A seleção das participantes foi realizada por meio de gerador de números aleatórios Intemodino Group. A identificação foi feita através de listagem nominal fornecida em cada unidade prisional.

\section{Instrumentos e variáveis coletadas}

Os dados foram coletados através de questionário autoaplicado, utilizando tecnologia de Audio Computer-Assisted Self-Interviewing ACASI, que consiste na utilização de tablets para as respostas dos questionários, proporcionando às entrevistadas maior sigilo e privacidade nas respostas. A opção pelo ACASI decorre da sua aplicabilidade em pesquisas nas quais existe a necessidade de se abordar informações sensíveis, de cunho pessoal, ou mesmo relacionadas a comportamentos de risco para a saúde ${ }^{15}$.

O Self-Reporting Questionnaire-20 (SRQ-20) foi utilizado para mensurar os níveis de suspeição para transtornos mentais comuns. O instrumento é composto por 20 questões, sendo as 4 primeiras relacionadas a sintomas físicos e outras 16 sobre sintomas psicoemocionais ${ }^{16,17}$.

A aplicação do SRQ-20 permite a detecção precoce de sinais e sintomas de comprometimento da saúde mental, que incluem fadiga, insônia, irritabilidade, além de aspectos subclínicos. É altamente recomendado para estudos de bases populacionais, especialmente em grupos de trabalhadores, tendo em vista a associação dos sinais e sintomas com a diminuição das funções laborais e sociais ${ }^{16,17}$.

Por se tratar de um instrumento de rastreamento, a determinação do ponto de corte para a detecção dos casos é fundamental para a garantia da sensibilidade e especificidade. Neste estudo, adotou-se o escore mínimo de 7 respostas afirmativas do SRQ-20 para as ASP, em conformidade com as orientações estabelecidas para mulheres $^{18-20}$.

O Alcohol Use Disorders Identification Test (AUDIT) foi utilizado para a identificação dos diferentes padrões de consumo de álcool entre ASP. O AUDIT é composto por 10 itens e avalia tanto o uso recente, como problemas relacionados ao consumo de álcool, além de sintomas de dependência ${ }^{21}$. Dentre as potencialidades do instrumento, destaca-se a facilidade e a rapidez na aplicação, além da possibilidade de fornecer orientações focadas no padrão de consumo do sujeito avaliado ${ }^{22}$. 
A classificação do consumo de álcool entre as ASP foi estratificada em duas categorias: baixo risco e de risco ou alto risco. O consumo de baixo risco refere-se às ASP que obtiveram de $0 \mathrm{a}$ 7 escores. $\mathrm{O}$ consumo de risco ou alto risco refere-se às que obtiveram acima de 8 escores após a aplicação do instrumento.

As definições de violência física, psicológica, sexual e moral utilizadas nesta pesquisa estão em conformidade com os conceitos adotados pela Organização Mundial da Saúde e da legislação vigente no Brasil ${ }^{23,24}$. As definições de violência física grave relacionam-se aos episódios envolvendo espancamento, queimaduras ou tentativas de enforcamento. As violências físicas severas relacionam-se a objetos que causaram ferimentos ou lesões corporais, tais como armas de fogo, agressões com facas ou instrumentos perfurocortantes.

A frequência das violências ou agressões sofridas pelas ASP nas unidades prisionais em que trabalha ou trabalhou foi dividida em duas categorias: autorrelato (sofrida pela própria ASP) ou conhecida (teve conhecimento de algum caso de violência sofrida por colega de trabalho).

No componente trabalho, foram investigadas a idade de ingresso no sistema prisional, tempo de trabalho como agente ( 5 anos ou menos; 6 a 10 anos; mais de 10 anos) e ocupações anteriores ao ingresso no sistema prisional. A definição sobre os tipos de estabelecimentos prisionais em que a ASP já trabalhou como cadeia pública, presídios, casas de privação provisória, penitenciária, colônia agrícola, casas de albergado e hospitais de custódia obedeceram às definições do Ministério da Justiça do Brasil ${ }^{25}$.

O consumo de calmantes refere-se aos medicamentos ansiolíticos adquiridos sem a necessidade de receituário médico no Brasil. Os benzodiazepínicos foram Rohypnol ${ }^{\circledR}$, Valium ${ }^{\circledR}$ ou Dormonid ${ }^{\circledR}$, cuja aquisição depende de receituário médico no país. Foram incluídas ainda questões sobre o consumo de cigarros (atual ou pregresso) e consumo de drogas ilícitas atualmente (maconha, crack, merla).

Aspectos socioeconômicos como idade, grau de instrução e número de filhos também foram investigados. A raça (parda, negra, branca e amarela) foi autorreferida, obedecendo aos critérios estabelecidos no Brasil. A renda mensal foi medida em salários mínimos e contabilizada em moeda local ${ }^{26}$.

\section{Análise dos dados}

Os dados foram analisados utilizando os softwares SPSS ${ }^{\circledast}$ versão 20.0 e Stata ${ }^{\circledast}$ versão 13. Foi realizado o teste de qui-quadrado de Pearson. O Odds Ratio e Intervalos de Confiança foram estimados para os fatores que apresentaram associação significativa ou mostraram-se como fatores de confundimento.

As estimativas pontuais e intervalares, bem como as análises de associação bivariada foram realizadas utilizando o módulo de amostragem complexa com a ponderação obtida pelo inverso do produto das probabilidades de escolha das ASP por estágio de amostragem. O nível de significância utilizado para os testes estatísticos foi $5 \%$. As frequências absolutas e relativas foram apresentadas, respectivamente, por meio das frequências não ponderadas e ponderadas.

A pesquisa foi aprovada pelo Comitê de Ética em Pesquisa, da Universidade Federal do Ceará/ PROPESQ. Por se tratar de pesquisas envolvendo seres humanos, todas as participantes concordaram e assinaram o Termo de Consentimento Livre e Esclarecido.

\section{Resultados}

A média de idade das ASP foi de 38,14 $( \pm 8,52)$ anos e 73,4\% (95\%IC: 68,0 - 78,1) encontram-se na faixa etária de 31 a 50 anos. Aproximadamente $44 \%$ se autodeclararam como negras e $37,7 \%$ como brancas. Quanto ao nível de escolaridade, 64,3\% (95\%IC: 58,6 - 69,6) frequentam a universidade, já completaram o ensino superior ou alguma pós-graduação (Tabela 1).

A média de idade para o ingresso das ASP no sistema prisional foi de $29,9( \pm 6,73)$ anos. A maior frequência está distribuída na faixa etária entre 25 a 35 anos. O tempo médio de trabalho como agente foi de $8,11( \pm 6,6)$ anos, sendo que 22,6\% (95\% IC: 18,3 - 27,4) trabalhavam há mais de 10 anos (Tabela 1).

Sobre ocupações pregressas, 91,5\% (95\%IC: 87,8 - 94,3) referiram trabalhar em outras atividades profissionais antes de ingressarem no sistema prisional. A maioria dessas, nunca desempenhou funções relacionadas à atividade de segurança nacional/particular. No que diz respeito à ocupação atual como ASP, 73\% já trabalharam em mais de um estabelecimento prisional (Tabela 1).

Com relação aos conhecimentos adquiridos para o exercício profissional, 94,7\% (95\%IC: 91,3 - 96,8) afirmaram ser suficientes na área de 
Tabela 1. Perfil socioeconômico, laboral e psicossocial das Agentes de Segurança Penitenciária.

\begin{tabular}{|c|c|c|c|}
\hline & $\mathrm{n}^{\mathrm{a}}$ & $\%^{\mathrm{b}}$ & $95 \% \mathrm{IC}^{\mathrm{b}}$ \\
\hline \multicolumn{4}{|l|}{ Idade (anos) } \\
\hline Media $( \pm d p)$ & 295 & 38,14 & $( \pm 8,52)$ \\
\hline$<30$ & $51 / 295$ & 15,3 & $11,8-19,8$ \\
\hline $31 \mid--36$ & $87 / 295$ & 30,0 & $24,8-35,7$ \\
\hline $36 \mid--40$ & $63 / 295$ & 22,4 & $17,8-27,8$ \\
\hline $40 \mid--50$ & $59 / 295$ & 21,0 & $16,4-26,6$ \\
\hline$\geq 50$ & $35 / 295$ & 11,3 & $8,1-15,6$ \\
\hline \multicolumn{4}{|l|}{ Raça } \\
\hline Parda & $41 / 293$ & 14,8 & $11,0-19,6$ \\
\hline Negra & $130 / 293$ & 44,1 & $38,4-50,0$ \\
\hline Branca & $111 / 293$ & 37,7 & $32,5-43,1$ \\
\hline Amarela & $11 / 293$ & 3,4 & $1,9-6,2$ \\
\hline \multicolumn{4}{|l|}{ Grau de Instrução } \\
\hline Ensino Fundamental ou Médio & $109 / 295$ & 35,7 & $30,4-41,4$ \\
\hline Ensino superior incompleto/ completo ou pós-graduação & $186 / 295$ & 64,3 & $58,6-69,6$ \\
\hline \multicolumn{4}{|l|}{ Renda mensal em Salários Mínimos } \\
\hline 1 a 3 Salários Mínimos & $62 / 294$ & 18,4 & $14,9-22,5$ \\
\hline De 3 a 5 Salários Mínimos & $132 / 294$ & 47,1 & $42,4-51,9$ \\
\hline 5 Salários Mínimos ou mais & $100 / 294$ & 34,5 & $30,6-38,7$ \\
\hline \multicolumn{4}{|l|}{ Trabalho no sistema prisional } \\
\hline \multicolumn{4}{|l|}{ Idade de ingresso no sistema penitenciário } \\
\hline Média $( \pm \mathrm{dp})$ & 294 & 29,9 & $( \pm 6,73)$ \\
\hline$\leq 25$ anos & $83 / 294$ & 28,8 & $23,5-34,6$ \\
\hline $25--\mid 35$ anos & $161 / 294$ & 53,7 & $47,5-59,8$ \\
\hline$>35$ anos & $50 / 294$ & 17,5 & $13,4-22,6$ \\
\hline \multicolumn{4}{|l|}{ Tempo de trabalho como agente } \\
\hline Média $( \pm \mathrm{dp})$ & 294 & 8,11 & $( \pm 6,61)$ \\
\hline 5 anos ou menos & $138 / 294$ & 45,8 & $40,2-51,5$ \\
\hline 6 a 10 anos & $92 / 294$ & 31,6 & $26,6-37,1$ \\
\hline Mais de 10 anos & $64 / 294$ & 22,6 & $18,3-27,4$ \\
\hline \multicolumn{4}{|l|}{ Ocupações pregressas ao ingresso no Sistema Prisional } \\
\hline Não & $26 / 289$ & 8,5 & $5,7-12,2$ \\
\hline Sim & $263 / 289$ & 91,5 & $87,8-94,3$ \\
\hline Militar, guarda, segurança, vigilante & $17 / 289$ & 6,0 & $3,7-9,6$ \\
\hline Não relacionada à atividade de segurança & $246 / 289$ & 85,5 & $80,8-89,3$ \\
\hline Trabalhou em outro estabelecimento prisional & $216 / 295$ & 73,0 & $68,0-77,5$ \\
\hline \multicolumn{4}{|l|}{ Quantos outros estabelecimentos penais trabalhou } \\
\hline 0 & $79 / 295$ & 27,0 & $22,5-32$ \\
\hline 1 & $162 / 295$ & 53,8 & $48,3-59,3$ \\
\hline 2 ou mais & $54 / 295$ & 19,2 & $15,3-23,8$ \\
\hline
\end{tabular}

segurança, 55,9\% (95\%IC: 49,8 - 61,8) sobre drogas ilícitas (maconha, merla, crack, etc.) e 54,5\% (95\%IC: 48,5 - 60,3) sobre drogas lícitas (álcool e tabaco) (Tabela 1 ).

No que tange aos componentes psicossociais, a quase totalidade das agentes considera seu trabalho como de risco e estressante. Pouco mais de
30\% (95\%IC: 25,2 - 36,6) das ASP apresentaram transtornos mentais comuns. O consumo atual de calmantes foi relatado por pouco mais de $22 \%$ das entrevistadas (Tabela 1).

Sobre o consumo de cigarros, 18,2\% (95\%IC: 14,2 - 23) das entrevistadas declararam já ter fumado alguma vez na vida. Contudo, apenas 12\% 
Tabela 1. continuação

\begin{tabular}{|c|c|c|c|}
\hline & $\mathbf{n}^{\mathrm{a}}$ & $\%^{\mathrm{b}}$ & $95 \% \mathrm{IC}^{\mathrm{b}}$ \\
\hline \multicolumn{4}{|l|}{ Tipos de estabelecimentos penais que já trabalhou } \\
\hline Cadeia pública & $14 / 295$ & 4,8 & $2,8-8,2$ \\
\hline Presídios ou casas de privação provisória & $100 / 295$ & 35,3 & $30,8-40,2$ \\
\hline Penitenciária & $137 / 295$ & 47,0 & $41,6-52,5$ \\
\hline Colônia agrícola & $10 / 295$ & 2,7 & $1,4-5,2$ \\
\hline Casas de albergado ou albergue & $13 / 295$ & 4,7 & $2,7-8,2$ \\
\hline Hospital de custódia e tratamento psiquiátrico & $13 / 295$ & 4,1 & $2,2-7,4$ \\
\hline Outro(a) local & $7 / 295$ & 2,5 & $1,1-5,2$ \\
\hline \multicolumn{4}{|l|}{ Considera seu trabalho na prisão } \\
\hline Apenas estressante & $5 / 291$ & 1,4 & $0,6-3,3$ \\
\hline Apenas de risco & $50 / 291$ & 17,9 & $13,5-23,0$ \\
\hline Risco e estressante & $236 / 291$ & 80,9 & $75,5-85,3$ \\
\hline \multicolumn{4}{|c|}{ Conhecimentos suficientes para prática profissional nas áreas de } \\
\hline Segurança & $262 / 278$ & 94,7 & $91,3-96,8$ \\
\hline Saúde mental & $100 / 278$ & 36,3 & $30,6-42,3$ \\
\hline Saúde reprodutiva & $57 / 278$ & 21,1 & $16,5-26,5$ \\
\hline Drogas lícitas (álcool e tabaco) & $152 / 278$ & 54,5 & $48,5-60,3$ \\
\hline Drogas ilícitas (maconha, merla, crack, etc.) & $154 / 278$ & 55,9 & $49,8-61,8$ \\
\hline \multicolumn{4}{|l|}{ Componente psicossocial } \\
\hline \multicolumn{4}{|l|}{ Escore SRQ-20 } \\
\hline$<7$ & $204 / 291$ & 69,4 & $63,4-74,8$ \\
\hline$\geq 7$ & $87 / 291$ & 30,6 & $25,2-36,6$ \\
\hline \multicolumn{4}{|l|}{ Consumo de Calmantes Atualmente } \\
\hline Não & $213 / 291$ & 72,7 & $67-77,7$ \\
\hline Sim & $78 / 291$ & 27,3 & $22,3-33$ \\
\hline \multicolumn{4}{|l|}{ Consumo de Cigarros } \\
\hline \multicolumn{4}{|l|}{ Fuma ou já fumou cigarros? } \\
\hline Não & $232 / 290$ & 81,8 & $77-85,8$ \\
\hline Sim & $58 / 290$ & 18,2 & $14,2-23$ \\
\hline Sim, atualmente & $39 / 290$ & 12,0 & $8,7-16,2$ \\
\hline Sim, mas parei & $19 / 290$ & 6,2 & $4,0-9,6$ \\
\hline \multicolumn{4}{|l|}{ Consumo de Bebidas Alcoólicas } \\
\hline Não & $193 / 285$ & 67,7 & $61,7-73,1$ \\
\hline Sim & $92 / 285$ & 32,3 & $26,9-38,3$ \\
\hline \multicolumn{4}{|l|}{ Classificação do Consumo - AUDIT } \\
\hline Baixo risco ou abstinência $(0-7)$ & $258 / 280$ & 91,5 & $87,1-94,5$ \\
\hline Consumo de risco ou alto risco & $22 / 280$ & 8,5 & $5,5-12,9$ \\
\hline
\end{tabular}

a: valores observados; ${ }^{\text {b: }}$ valores ponderados.

permanecem com hábitos tabagistas. Cerca de 32,3\% (95\%IC: 26,9 - 38,3) das ASP afirmaram consumir bebidas alcoólicas (Tabela 1).

Os eventos envolvendo violência contra as ASP merecem destaque. Apenas 3,7\% do total das entrevistadas declararam não saber e/ou não querer responder se já sofreram algum episódio de violência no ambiente de trabalho. Esse percentual foi ainda menor $(1,4 \%)$ quando se tratou do conhecimento em relação à violência sofrida por colegas de profissão (Tabela 2).

Cerca de 68,4\% (95\%IC: 62,5 - 73,8) das ASP declararam ter conhecimento de eventos envolvendo violência com colegas de trabalho na prisão. Já para a violência autorreferida, o percentual foi de 33,7\% (95\%IC: 28,2 - 39,4) (Tabela 2).

Quando estratificadas por tipo, o conhecimento sobre violências sofridas por colegas de 
Tabela 2. Violências sofridas por ASP e/ou colegas de profissão na unidade prisional que trabalha atualmente ou em outra unidade que trabalhou.

\begin{tabular}{|c|c|c|c|c|c|c|}
\hline \multirow{2}{*}{ Violência sofrida } & \multicolumn{3}{|c|}{ Colega de trabalho } & \multicolumn{3}{|c|}{ ASP } \\
\hline & $\mathbf{n} / \mathbf{N}^{*}$ & $\%^{* *}$ & $95 \% \mathrm{IC}^{* *}$ & $\mathbf{n} / \mathbf{N}^{*}$ & $\%^{* *}$ & $95 \% \mathrm{IC}^{* *}$ \\
\hline Teve conhecimento de violência na prisão & $197 / 291$ & 68,4 & $62,5-73,7$ & $93 / 291$ & 33,7 & $28,2-39,4$ \\
\hline \multicolumn{7}{|l|}{ No de violências sofridas ou conhecidas } \\
\hline 0 & $94 / 291$ & 31,6 & $26,3-37,5$ & $190 / 284$ & 66,3 & $60,5-71,7$ \\
\hline $1-2$ & $94 / 291$ & 32,5 & $27,0-38,5$ & $81 / 284$ & 28,4 & $23,1-34,3$ \\
\hline$\geq 3$ & $103 / 291$ & 35,8 & $30,4-41,7$ & $13 / 284$ & 5,3 & $3,1-8,9$ \\
\hline \multicolumn{7}{|l|}{ Tipo de violência que teve conhecimento } \\
\hline Roubo & $109 / 292$ & 38,4 & $32,7-44,4$ & $31 / 292$ & 11,6 & $8,1-16,3$ \\
\hline Violência moral a & $87 / 287$ & 30,9 & $25,7-36,6$ & $30 / 287$ & 11,1 & $7,7-15,7$ \\
\hline Violência psicológica ${ }^{\mathrm{b}}$ & $119 / 282$ & 42,2 & $36,2-48,4$ & $63 / 282$ & 22,8 & $18,1-28,4$ \\
\hline Assédio sexual ${ }^{\mathrm{c}}$ & $24 / 281$ & 8,7 & $5,7-13,0$ & $9 / 281$ & 3,1 & $1,5-6,3$ \\
\hline Violência física & $116 / 282$ & 42,5 & $36,8-48,4$ & $13 / 278$ & 4,1 & $2,3-7,0$ \\
\hline Violência física leve ${ }^{\mathrm{d}}$ & $106 / 283$ & 38,9 & $33,4-44,8$ & $12 / 283$ & 3,7 & $2,1-6,6$ \\
\hline Violência física grave e/ou severa & $90 / 285$ & 31,7 & $26,6-37,3$ & $2 / 282$ & 0,7 & $0,2-3,1$ \\
\hline Violência física grave ${ }^{\mathrm{e}}$ & $61 / 282$ & 22,1 & $17,5-27,3$ & $1 / 282$ & 0,5 & $0,1-3,3$ \\
\hline Violência física severa ${ }^{\mathrm{f}}$ & $58 / 285$ & 20,0 & $15,6-25,1$ & $1 / 282$ & 0,3 & $0,0-1,9$ \\
\hline \multicolumn{7}{|l|}{ Objeto usado na violência física severa } \\
\hline Faca ou objeto perfurante & $31 / 285$ & 9,4 & $6,6-13,2$ & $1 / 282$ & 0,3 & $0,0-1,9$ \\
\hline Revolver ou outra arma de fogo & $12 / 285$ & 5,0 & $2,8-8,9$ & $0 / 282$ & 0,0 & - \\
\hline Outros objetos que causam ferimento & $7 / 285$ & 2,4 & $1,1-5,4$ & $0 / 282$ & 0,0 & - \\
\hline Faca ou objeto perfurante e revolver & $3 / 285$ & 1,2 & $0,4-4,0$ & $0 / 282$ & 0,0 & - \\
\hline Faca ou objeto perfurante e outro & $5 / 285$ & 1,9 & $0,8-4,6$ & $0 / 282$ & 0,0 & - \\
\hline
\end{tabular}

": valores observados; ${ }^{* *}$ : valores ponderados.

${ }^{a}$ : acusada injustamente de ter cometido algum delito ou ter sido acusada de atitudes que consideram vergonhosas. ${ }^{\text {b: }}$ ameaçada, humilhada, chantageada, perseguida ou ridicularizada. ${ }^{c}$ : tentativa de manter relações íntimas ou qualquer conduta que considera sexual. d: tapa no rosto, empurrões, beliscões ou puxões de cabelos de propósito. é: esbofeteada, espancada, queimada ou tentativa de enforcamento. f: ferida de propósito com faca, outro objeto perfurocortante, revólver ou outra arma de fogo, além de outros objetos que causaram ferimento (casca de pilha, caneta, etc.).

trabalho permanece com uma maior frequência do que entre as relatadas pelas próprias entrevistadas, distribuídas respectivamente da seguinte maneira: violência física 42,5\% (95\%IC: 36,8 - 48,4) e 4,1\% (95\%IC: 2,3 - 7,0); psicológica 42,2\% (95\%IC: $36,2-48,4$ ) e $22,8 \%$ (95\%IC: $18,1-28,4)$; roubo $38,4 \%$ (95\%IC: $32,7-44,4)$ e 11,6\% (95\%IC: 8,1 - 16,3); violência moral 30,9\% (95\%IC: 25,7 - 36,6) e 11,1\% (95\%IC: 7,7 - 15,7). O conhecimento sobre pelo menos 3 ou mais formas de violências sofridas pelas colegas de trabalho foi de $35,8 \%$ e de 5,3\% (95\%IC: 3,1 $8,9 \%$ ) com a própria ASP (Tabela 2).

Para todos os tipos de violências sofridas, as detentas e as próprias ASP aparecem como as principais suspeitas de execução. Contudo, a natureza das agressões difere para ambas. Conforme se observa na Tabela 3, as detentas foram as mais citadas como suspeitas de praticarem violência física grave e severa 93,1\% (95\%IC: 80,3
- 97,8), violência física leve 89,4\% (95\%IC: 79,6 $94,8)$ e violência psicológica 52,4\% (95\%IC: 43,0 - 61,5) (Tabela 3).

Chama a atenção o fato de as próprias ASP serem apontadas como as principais suspeitas de praticarem violência contra as colegas de trabalho. Dentre os tipos, destacam-se os roubos [74,6\% (95\%IC: 62,3 - 84,0\%)], violência moral [68,1\% (95\%IC: 55,9-78,3\%)] e assédio sexual [66,8\% (95\%IC: 43,1 - 84,3\%)] (Tabela 3).

A Tabela 4 refere-se à análise de associação entre os fatores socioeconômicos, psicossociais e de trabalho com a violência autorreferida pelas ASP no sistema prisional. A idade de ingresso das ASP no sistema prisional demonstrou forte associação para a ocorrência de violência no trabalho. As ASP que ingressaram na faixa etária de 25 a 35 anos possuem as maiores chances ( $\mathrm{OR}=4,06$ (95\%IC: 1,6 - 10,8)) de sofrerem violência no ambiente de trabalho, seguidas das que ingressa- 
Tabela 3. Pessoas suspeitas de praticarem violência na unidade prisional em que a ASP trabalha.

\begin{tabular}{|c|c|c|c|}
\hline & $\mathrm{n} / \mathrm{N}^{\mathrm{a}}$ & $\%^{\mathrm{b}}$ & $95 \% \mathrm{IC}^{\mathrm{b}}$ \\
\hline \multicolumn{4}{|l|}{ Pessoas suspeitas de cometer roubo } \\
\hline Presidiárias/Detentas & $24 / 73$ & 32,9 & $22,6-45,0$ \\
\hline ASP & $55 / 73$ & 74,6 & $62,3-84,0$ \\
\hline Policiais e/ou outros funcionários da prisão & $6 / 73$ & 7,8 & $3,5-16,6$ \\
\hline Visitante & $4 / 73$ & 6,4 & $2,4-16,0$ \\
\hline Outro(a) & $5 / 73$ & 8,8 & $3,4-20,6$ \\
\hline \multicolumn{4}{|l|}{ Pessoas suspeitas de cometer violência moral } \\
\hline Presidiárias/ Detentas & $30 / 81$ & 38,8 & $27,9-50,9$ \\
\hline ASP & $55 / 81$ & 68,1 & $55,9-78,3$ \\
\hline Policiais e/ou outros funcionários da prisão & $18 / 81$ & 23,5 & $14,7-35,5$ \\
\hline Visitante & $8 / 81$ & 9,9 & $4,8-19,2$ \\
\hline Outro(a) & $2 / 81$ & 1,3 & $0,3-5,7$ \\
\hline \multicolumn{4}{|l|}{ Pessoas suspeitas de cometer violência psicológica } \\
\hline Presidiárias/ Detentas & $61 / 116$ & 52,4 & $43,0-61,5$ \\
\hline ASP & $49 / 116$ & 39,8 & $30,7-49,7$ \\
\hline Policiais e/ou outros funcionários da prisão & $24 / 116$ & 22,6 & $15,3-32,0$ \\
\hline Visitante & $13 / 116$ & 11,6 & $6,8-19,2$ \\
\hline Outro(a) & $6 / 116$ & 4,6 & $1,9-10,7$ \\
\hline \multicolumn{4}{|l|}{ Pessoas suspeitas de cometer assédio sexual } \\
\hline Presidiárias/ Detentas & $9 / 21$ & 37,4 & $19,2-60,1$ \\
\hline ASP & $14 / 21$ & 66,8 & $43,1-84,3$ \\
\hline Policiais e ou outros funcionários da prisão & $0 / 21$ & 0,0 & - \\
\hline Visitante & $6 / 21$ & 33,2 & $15,7-56,9$ \\
\hline Outro(a) & $1 / 21$ & 4,8 & $0,7-27,5$ \\
\hline \multicolumn{4}{|l|}{ Pessoas suspeitas de cometer violência física leve } \\
\hline Presidiárias/ Detentas & $85 / 93$ & 89,4 & $79,6-94,8$ \\
\hline ASP & $8 / 93$ & 9,6 & $4,7-18,9$ \\
\hline Policiais e/ou outros funcionários da prisão & $0 / 93$ & 0,0 & - \\
\hline Visitante & $2 / 93$ & 2,5 & $0,6-10,0$ \\
\hline Outro(a) & $0 / 93$ & 0,0 & - \\
\hline \multicolumn{4}{|l|}{ Pessoas suspeitas de cometer violência física grave } \\
\hline Presidiárias/ Detentas & $44 / 47$ & 93,1 & $80,3-97,8$ \\
\hline ASP & $3 / 47$ & 6,9 & $2,2-19,7$ \\
\hline Policiais e/ou outros funcionários da prisão & $0 / 47$ & 0,0 & - \\
\hline Visitante & $0 / 47$ & 0,0 & - \\
\hline Outro(a) & $1 / 47$ & 1,2 & $0,2-8,2$ \\
\hline \multicolumn{4}{|l|}{ Pessoas suspeitas de cometer violência física severa } \\
\hline Presidiárias/ Detentas & $39 / 42$ & 93,1 & $80,3-97,8$ \\
\hline ASP & $2 / 42$ & 3,9 & $1,0-14,3$ \\
\hline Policiais e/ou outros funcionários da prisão & $1 / 42$ & 2,0 & $0,3-12,9$ \\
\hline Visitante & $1 / 42$ & 1,5 & $0,2-10,0$ \\
\hline Outro(a) & $2 / 42$ & 8,8 & $2,2-29,4$ \\
\hline
\end{tabular}

${ }^{\mathrm{a}}$ : valores observados $;$ : valores ponderados.

ram no sistema prisional com menos de 25 anos [OR = 3,66 (95\%IC: 1,38 - 9,75)] (Tabela 4).

As ASP que já trabalharam em outro estabelecimento prisional tiveram mais chances de sofrer violência quando comparadas às que nunca trabalharam em outro estabelecimento prisional [OR = 4,04 (95\%IC: 1,95 - 8,37)]. Quando considerados os números de estabelecimentos prisionais em que trabalharam, a chance de sofrer violência foi maior para o grupo das ASP que 
Tabela 4. Análise de associação entre os fatores socioeconômicos, psicossociais, de violência antes do ingresso no sistema penitenciário e de trabalho com a violência auto referida pelas ASP no sistema prisional.

\begin{tabular}{|c|c|c|c|c|c|}
\hline & \multicolumn{5}{|c|}{ Violência com a ASP } \\
\hline & $\mathrm{n} / \mathrm{N}^{\mathrm{a}}$ & $\%^{a}$ & OR & 95\%CI & p-value \\
\hline \multicolumn{6}{|l|}{ Idade (anos) } \\
\hline $21--\mid 30$ anos & $12 / 51$ & 27,2 & 1,48 & $0,52-4,20$ & 0,094 \\
\hline $30--\mid 50$ anos & $73 / 200$ & 37,2 & 2,35 & $1,00-5,49$ & \\
\hline$\geq 50$ anos & $9 / 33$ & 20,1 & 1,00 & - & \\
\hline \multicolumn{6}{|l|}{ Raça } \\
\hline Negra & $15 / 38$ & 34,5 & 1,27 & $0,56-2,85$ & 0,439 \\
\hline Parda & $36 / 125$ & 29,3 & 1,00 & - & \\
\hline Branca & $39 / 109$ & 37,8 & 1,47 & $0,80-2,67$ & \\
\hline \multicolumn{6}{|l|}{ Grau de instrução } \\
\hline Ensino fundamental ou médio & $38 / 105$ & 39,2 & 1,46 & $0,85-2,52$ & 0,172 \\
\hline Ensino superior incompleto/ completo ou pós & $56 / 179$ & 30,6 & 1,00 & - & \\
\hline \multicolumn{6}{|l|}{ Renda mensal em Salários Mínimos } \\
\hline Mais de 1 a 3 salários mínimos & $14 / 56$ & 24,3 & 1,00 & - & 0,121 \\
\hline Mais de 3 a 5 (R\$ 2035 a $R \$ 3390)$ & $40 / 132$ & 32,2 & 1,48 & $0,70-3,13$ & \\
\hline Mais de 5 salários mínimos & $40 / 95$ & 40,8 & 2,15 & $1,00-4,55$ & \\
\hline \multicolumn{6}{|l|}{ Idade que ingressou no presidio } \\
\hline$\leq 25$ anos & $27 / 82$ & 36,7 & 3,66 & $1,38-9,75$ & \\
\hline $25--\mid 35$ anos & $60 / 152$ & 39,1 & 4,06 & $1,6-10,28$ & \\
\hline$>35$ anos & $7 / 49$ & 13,7 & 1,00 & - & 0,008 \\
\hline \multicolumn{6}{|l|}{ Tempo em que trabalha como agente } \\
\hline 5 anos ou menos & $35 / 134$ & 27,5 & 1,00 & - & 0,114 \\
\hline 6 a 10 anos & $36 / 88$ & 39,6 & 1,73 & $0,95-3,16$ & \\
\hline Mais de 10 anos & $23 / 61$ & 38,8 & 1,68 & $0,90-3,11$ & \\
\hline \multicolumn{6}{|l|}{ Trabalhou em outro estabelecimento prisional } \\
\hline Sim & $83 / 207$ & 40,8 & 4,04 & $1,95-8,37$ & $<0,001$ \\
\hline Não & $11 / 77$ & 14,6 & 1,00 & - & \\
\hline \multicolumn{6}{|l|}{ Quantos outros estabelecimentos penais trabalhou } \\
\hline 0 & $11 / 77$ & 14,6 & 1,00 & - & $<0,001$ \\
\hline 1 & $55 / 154$ & 35,5 & 3,23 & $1,51-6,90$ & \\
\hline 2 ou mais & $28 / 53$ & 55,2 & 7,22 & $3,08-16,92$ & \\
\hline \multicolumn{6}{|l|}{ Estabelecimentos penais que já trabalhou } \\
\hline \multicolumn{6}{|l|}{ Cadeia pública } \\
\hline Sim & $6 / 13$ & 45,0 & 1,65 & $0,50-5,42$ & 0,403 \\
\hline Não & $88 / 271$ & 33,2 & 1,00 & - & \\
\hline \multicolumn{6}{|l|}{ Presídios ou Casas de privação provisória } \\
\hline Sim & $38 / 96$ & 42,3 & 1,80 & $1,07-3,03$ & 0,026 \\
\hline Não & $56 / 188$ & 28,9 & 1,00 & - & \\
\hline \multicolumn{6}{|l|}{ Penitenciária } \\
\hline Sim & $54 / 133$ & 42,6 & 2,16 & $1,28-3,63$ & 0,004 \\
\hline Não & $40 / 151$ & 25,6 & 1,00 & - & \\
\hline \multicolumn{6}{|l|}{ Considera trabalho na prisão um trabalho de risco } \\
\hline Sim & $92 / 275$ & 34,0 & - & - & - \\
\hline Não & $2 / 4$ & 42,8 & & & \\
\hline \multicolumn{6}{|c|}{ Considera trabalho na prisão um trabalho estressante } \\
\hline Sim & $82 / 230$ & 36,0 & 1,82 & $0,81-4,09$ & 0,146 \\
\hline Não & $11 / 48$ & 23,7 & 1,00 & - & \\
\hline
\end{tabular}


Tabela 4. continuação

\begin{tabular}{|c|c|c|c|c|c|}
\hline & \multicolumn{5}{|c|}{ Violência com a ASP } \\
\hline & $\mathbf{n} / \mathbf{N}^{a}$ & $\%^{\mathrm{a}}$ & OR & 95\%CI & p-value \\
\hline \multicolumn{6}{|c|}{$\begin{array}{l}\text { Considera ter conhecimentos suficientes para pratica } \\
\text { profissional nas seguintes áreas }\end{array}$} \\
\hline \multicolumn{6}{|l|}{ Segurança } \\
\hline Sim & $84 / 252$ & 33,9 & 1,01 & $0,31-3,26$ & 0,999 \\
\hline Não & $5 / 16$ & 33,8 & 1,00 & - & \\
\hline \multicolumn{6}{|l|}{ Saúde mental } \\
\hline Sim & $34 / 95$ & 37,8 & 1,30 & $0,74-2,3$ & 0,356 \\
\hline Não & $55 / 173$ & 31,8 & 1,00 & - & \\
\hline \multicolumn{6}{|l|}{ Drogas lícitas (álcool e tabaco) } \\
\hline Sim & $57 / 147$ & 38,8 & 1,62 & $0,91-2,87$ & 0,098 \\
\hline Não & $32 / 121$ & 28,1 & 1,00 & - & \\
\hline \multicolumn{6}{|c|}{ Drogas ilícitas (maconha, merla, crack, etc.) } \\
\hline Sim & $59 / 149$ & 39,6 & 1,79 & $1,00-3,21$ & 0,048 \\
\hline Não & $30 / 119$ & 26,7 & 1,00 & - & \\
\hline \multicolumn{6}{|l|}{ Escore SRQ-20 } \\
\hline$<7$ & $56 / 197$ & 29,7 & 1,00 & - & \\
\hline$\geq 7$ & $38 / 83$ & 44,2 & 1,879 & $1,06-3,30$ & 0,028 \\
\hline \multicolumn{6}{|l|}{ Escore AUDIT } \\
\hline Consumo de risco ou alto risco & $8 / 20$ & 45,4 & 1,791 & $0,68-4,66$ & 0,227 \\
\hline Baixo risco ou abstinência & $80 / 251$ & 31,7 & 1,000 & - & \\
\hline \multicolumn{6}{|c|}{ Utiliza algum tipo de calmante atualmente } \\
\hline Sim & $43 / 75$ & 58,7 & 4,304 & $2,38-7,77$ & $<0,001$ \\
\hline Não & $51 / 205$ & 24,8 & 1,000 & - & \\
\hline
\end{tabular}

${ }^{\mathrm{a}}$ : valores observados; ${ }^{\mathrm{b}}$ : valores ponderados.

trabalhou em dois ou mais presídios [OR $=7,22$ (95\%IC: 3,08 - 16,92)]. A chance de sofrer violência aumenta para as mulheres que trabalharam em casas de privação provisória $[\mathrm{OR}=1,80$ (95\%IC: 1,07 - 3,03)] (Tabela 4).

As ASP que obtiveram transtornos mentais comuns possuem mais chances de sofrer violência no ambiente prisional $[\mathrm{OR}=1,879$ (95\%IC: 1,069 - 3,305)]. O uso atual de calmantes que não necessitam de prescrição médica apresentou forte associação com os episódios envolvendo violência no trabalho [OR = 4,304 (95\%IC: 2,382 - 7,779)] (Tabela 4).

\section{Discussão}

As ASP que trabalharam em mais de um estabelecimento prisional apresentaram as maiores chances de sofrerem violências no trabalho. Quase $2 / 3$ da população de estudo referiu trabalhar em mais de uma unidade prisional. As profissionais que trabalharam em Casas de Privação Pro- visória obtiveram maiores chances de sofrerem violência no trabalho.

No Brasil, as Casas de Privação Provisória foram criadas com o objetivo de encarcerar presos que ainda não foram julgados pelos seus crimes. No país, cerca de $30 \%$ das mulheres custodiadas no sistema prisional aguardam seu julgamento pela justiça. O elevado número de presas nessas condições repercute diretamente na superlotação dessas instituições, deixando detentas e agentes mais expostas às práticas de violência e agressões ${ }^{13}$.

As ASP que ingressaram no sistema prisional com menos de 35 anos apresentam mais chances de sofrer violência no trabalho quando comparadas com as demais faixas etárias. Trabalhadores com menos de 30 anos foram apontados como as principais vítimas de violência no ambiente de trabalho em Portugal. Esse fenômeno pode ser explicado devido ao maior grau de escolaridade com que profissionais nesta faixa etária ingressam no mercado de trabalho. Isto pode contribuir para o desenvolvimento de sentimentos de ameaça, insegurança e competição quanto à per- 
manência no emprego entre os colegas de trabalho, fomentando práticas de violência ${ }^{27}$.

Mais da metade das ASP declararam ter conhecimento sobre episódios de violência com colegas de trabalho na prisão. Para a violência autorreferida, cerca de 33,7\% das entrevistadas afirmaram ter sofrido de um a três episódios no exercício das suas atividades profissionais. Nossos achados corroboram com os divulgados em pesquisa sobre violência no trabalho realizada na Inglaterra e no País de Gales. De acordo com o estudo, os ASP fazem parte do grupo de trabalhadores mais expostos a violências. Em geral, essa população apresenta um alto percentual de eventos de natureza ocupacional, cerca de 7,3\%. Esse valor é 10 vezes superior à média encontrada para as demais ocupações do país ${ }^{3}$.

Os resultados do nosso estudo também demonstraram significativo percentual para o autorrelato de violência psicológica $(22,8 \%)$ e violência moral $(11,1 \%)$. Em ambos os casos, as próprias ASP foram citadas como as principais suspeitas de praticarem os atos. Agressões verbais e ameaças entre colegas de trabalho costumam ser motivadas por sentimentos de inveja, ciúme, competição ou visando obter vantagens pessoais para uma promoção funcional. Isso traz implicações negativas para a saúde mental das ASP, tornando-as mais propensas a problemas de natureza psicológica ${ }^{27}$.

Além disso, situações em que os próprios colegas de trabalho são apontados como os principais suspeitos de praticarem ameaças ou agressões revelam um cenário de baixo suporte social. O suporte social entre colegas de trabalho é referenciado como um importante mecanismo para aliviar os efeitos negativos entre os trabalhadores após a ocorrência de episódios envolvendo agressões e violências, contribuindo para o reestabelecimento do seu bem estar físico e emocional ${ }^{4}$. É responsável ainda por atenuar o estresse e o sofrimento psicológico ${ }^{28,29}$.

O suporte social desenvolvido entre colegas de trabalho e supervisores têm sido associado a um maior bem estar entre os ASP, fortalecendo os laços de cooperação e solidariedade entre os profissionais $^{30}$. Em ambientes prisionais onde esses laços são frágeis, ou mesmo inexistentes, identifica-se uma considerável sobrecarga de estresse ocupacional entre os profissionais ${ }^{10}$.

O estresse no ambiente de trabalho apresenta forte associação com o aumento de agressões interpessoais e a diminuição da produtividade na execução das atividades laborais. Além disso, o estresse no ambiente de trabalho está associa- do à ocorrência de intimidações, assédio moral e sexual entre os próprios colegas de profissão ${ }^{31}$.

Em nosso estudo, 80,9\% das ASP consideraram seu trabalho como de risco e estressante. O trabalho também foi considerado estressante para 70\% dos participantes de uma pesquisa realizada com 167 ASP de duas unidades prisionais de Paris $^{32}$.

Estima-se que aproximadamente $42,1 \%$ dos ASP no mundo apresentam quadros de estresse relacionado ao trabalho ${ }^{33}$. Esse percentual pode ser considerado elevado, principalmente quando comparado com a população geral, cuja prevalência varia de 19 a $30 \%{ }^{34}$.

No caso dos ASP no Brasil, o sentimento de estresse no trabalho é reforçado pela superlotação das unidades prisionais e baixo efetivo de profissionais no sistema carcerário. Isto contribui para a ocorrência de fugas em massa e rebeliões, pondo em risco a integridade física e mental de ASP e detentos. No dia 1 de Janeiro de 2017 ocorreu uma das mais violentas rebeliões da história do sistema penitenciário no país, em Manaus, região Norte. Informações oficiais da Secretaria de Segurança Pública do Estado do Amazonas confirmaram a morte de 56 detentos e a fuga de pelo menos 130 presos. Além disso, presos e ASP foram feitos reféns $s^{35}$.

Desse modo, a tensão constante, o medo de rebeliões e a exposição quase que cotidiana a eventos violentos faz com que o trabalho dos ASP seja reconhecidamente estressante ${ }^{36}$. Esses fatores tornam o clima de trabalho desagradável, penoso e fatigante, mesmo quando comparado a outras ocupações estressantes como policiais, motoristas de transportes públicos, profissionais de saúde e educação ${ }^{37}$.

Os ASP são uma categoria profissional reconhecidamente exposta ao risco de desenvolverem distúrbios relacionados à saúde mental. Nossos achados evidenciaram que quase metade das ASP (44,2\%) que relataram ter sofrido violência no trabalho, apresentaram transtornos mentais comuns. Uma investigação realizada com 1.738 ASP de unidades prisionais federais dos Estados Unidos objetivou mensurar o potencial impacto das condições de trabalho para a saúde mental desses profissionais. A maioria dos participantes $(68,1 \%)$ relatou problemas de concentração e sinais de depressão ${ }^{38}$.

Como forma de aliviar os sintomas decorrentes do estresse e tensão no trabalho, muitos ASP recorrem ao uso de antidepressivos e calmantes. Nossos resultados demonstraram que $58,7 \%$ das profissionais que referiram o uso de calmantes já 
sofreram violência no trabalho. Esse indicador é importante para avaliar as repercussões das condições de trabalho na saúde mental das ASP.

\section{Conclusão}

A violência no ambiente carcerário brasileiro atinge tanto as ASP como as detentas. Os fatores causais não se limitam apenas às condições degradantes de encarceramento, nem tampouco à superlotação e precariedade do trabalho das agentes prisionais.

A violência nas unidades prisionais do Brasil deve ser compreendida como produto da exclusão social de grande parcela da população mais carente do país. Em um sentido mais amplo, trata-se da violência estrutural, que se expressa na ausência de direitos básicos como condições de moradia adequada, saúde, trabalho e educação de qualidade.

Dessa forma, tanto ASP como detentas são vítimas de uma organização social marcada por desigualdades sociais, econômicas e culturais, que permeiam as relações sociais no Brasil. A violência contra as ASP é mais um importante vetor desse complexo fenômeno multicausal.

Nesse sentido, a adoção de medidas restritas apenas ao ambiente de trabalho das ASP não são suficientes para torna-lo mais seguro e menos violento. É preciso a incorporação de um conjunto de ações e medidas intersetoriais, desenvolvidas dentro e fora das unidades prisionais. Capaz de alcançar tanto ASP como a sociedade em geral, numa perspectiva de enfrentamento das desigualdades sociais que se reproduzem no interior das unidades prisionais brasileiras.

\section{Colaboradores}

MJM Ferreira, RHM Macena, RMS Mota, RJ Pires Neto, AMC Silva, LJES Vieira, BC Kendall e LRFS Kerr contribuíram igualmente em todas as seções do artigo. 


\section{Referências}

1. Organização Mundial da Saúde (OMS). Relatório Mundial sobre a Prevenção da Violência. São Paulo: OMS; 2014.

2. International Labour Organization. Directrices Marco para afrontar la violencia laboral en el sector de la salud. Ginebra: World Health Organization; 2002.

3. Buckley P. Violence at work: Findings from the Crime Survey for England and Wales 2011/12. London: Health and Safety Executive and Office for National Statistics; 2013.

4. Gadegaard C, Andersen L, Hogh A. Effects of Violence Prevention Behavior on Exposure to Workplace Violence and Threats A Follow-Up Study. Journal of Interpersonal Violence 2015 ; 1(22):1-22.

5. Alves V, Binder M. Trabalhar em penitenciárias: violência referida pelos trabalhadores e (in) satisfação no trabalho. Revista Brasileira de Saúde Ocupacional. 2014; 39(129):5062.

6. Foucault M. Vigiar e punir: nascimento da prisão. Petrópolis: Vozes; 1987.

7. Konda S, Reichard AA, Tiesman HM. Occupational injuries among US correctional officers, 1999-2008. Journal of Safety Research 2012; 43(3):181-186.

8. Konda S, Tiesman H, Reichard A, Hartley D. US correctional officers killed or injured on the job. Corrections today 2013; 75(5):122-123.

9. Dares Analyses. Les Risques Professionnels en 2010: des fortes différences d'esposition selon les secteurs in 2010-2013. Paris: Ministére du Travail, de L'emplot, de la Formation Professionnelle et du Dialogue Social; 2013.

10. Lavigne É, Bourbonnais R. Psychosocial work environment, interpersonal violence at work and psychotropic drug use among correctional officers. Int J Law Psychiatry 2010; 33(2):122-129.

11. Prati G, Boldrin S. Organizational stressors, exposure to critical incidents and organizational well-being among correctional officers. Giornale italiano di medicina del lavoro ed ergonomia. 2010; 33(3 Supl B.):B33-B39.

12. Cashmore A, Indig D, Hampton S, Hegney D, Jalaludin B. Workplace violence in a large correctional health service in New South Wales, Australia: a retrospective review of incident management records. BMC Health Serv Res 2012; $12: 245$.

13. Brasil. Levantamento Nacional de Informações Penitenciárias. Brasília: Departamento Penitenciário Nacional; 2014.

14. Brasil. Lei $\mathrm{n}^{\circ} 7.210$, de 11 de Julho de 1984. Institui a Lei de Execução Penal. Diário Oficial da União 1984; 13 jul.

15. Simões AM, Bastos FI. Audio Computer-Assisted Interview: uma nova tecnologia em avaliação de comportamento de risco em doenças sexualmente transmissíveis, HIV e uso de drogas. Cad Saude Publica 2004; 20(5):1169-1181.

16. Coelho FMC, Pinheiro RT, Horta BL, Magalhães PVS, Garcias CMM, Silva CV. Common mental disorders and chronic non-communicable diseases in adults: a population-based study. Cad Saude Publica 2009; 25(1):59-67.

17. Santos KOB, Araújo TM, Pinho PS, Silva ACC. Avaliação de um instrumento de mensuração de morbidade psíquica: estudo de validação do self-reporting questionnaire (SRQ20). Revista Baiana de Saúde Pública 2011; 34(3):544-560.

18. Alves V. Condições de trabalho de funcionários penitenciários de Avaré-SP e ocorrência de transtornos mentais comuns [dissertação]. Botucatu: Faculdade de Medicina de Botucatu; 2009.

19. Organização Mundial da Saúde (OMS). Relatório Mundial da Saúde: saúde mental, novas concepções, nova esperança. Lisboa: OMS; 2002.

20. Tavares JP. Distúrbios psíquicos menores em enfermeiros docentes [tese]. Santa Maria: Universidade Federal de Santa Maria; 2010.
21. Martins RA, Manzatto AJ, Cruz LN, Poiate SMG, Carin ACCF. Utilização do Alcohol Use Disorders Identification Test (AUDIT) para identificação do consumo de álcool entre estudantes do ensino médio. International Journal of Psycology 2008; 42(2):307-316.

22. Moretti-Pires RO, Corradi-Webster CM. Adaptação e validação do Alcohol Use Disorders Identification Test (AUDIT) para a população ribeirinha do interior da Amazônia, Brasil. Cad Saude Publica 2011; 27(3):497-509.

23. World Health Organization (WHO). Directrices macro para afrontar la violencia laboral em el setor de la salud. Genevre: WHO; 2002.

24. Brasil. Lei no 11.340, de 7 de Agosto de 2006. Cria mecanismos para coibir a violência doméstica e familiar contra a mulher, nos termos do $\$ 80$ do art. 226 da Constituição Federal, da Convenção sobre a Eliminação de Todas as Formas de Discriminação contra as Mulheres e da Convenção Interamericana para Prevenir, Punir e Erradicar a Violência contra a Mulher; dispõe sobre a criação dos Juizados de Violência Doméstica e Familiar contra a Mulher; altera o Código de Processo Penal, o Código Penal e a Lei de Execução Penal; e dá outras providências.. Diário Oficial da União 2006; 8 ago.

25. Instituto Brasileiro de Geografia e Estatística (IBGE). CENSO demográfico 2014. Rio de Janeiro: Estudos \& Pesquisas; 2015.

26. Brasil. Ministério da Justiça. Estabelecimentos Prisionais. Portal do Ministério da Justiça do Brasil; 2015. [acessado 2015 jul 9]. Disponível em: http://portal.mj.gov.br/ main.asp?View =\%7BD574E9CE-3C7D-437A-A5B622166AD2E896\%7D\&BrowserType $=$ NN\&LangID $=p-$ tbr\&params $=$ itemID\%3D\%7BAB2EF2D9-2895-476E8516-E63C78FC7C4C\% 7D\%3B \&UIPartUID=\% 7 B2868B A3C-1C72-4347-BE11-A26F70F4CB26\%7D.

27. Piñuel YZ. Mobbing: como sobreviver ao assédio psicológico no trabalho. São Paulo: Edições Loyola; 2003.

28. Einarsen S. The nature, causes and consequences of bullying at work: The Norwegian experience. Perspectives interdisciplinaires sur le travail et la santé 2005; (7-3).

29. Cooper CL, Hoel H, Faragher B. Bullying is detrimental to health, but all bullying behaviours are not necessarily equally damaging. British Journal of Guidance \& Counselling 2004; 32(3):367-387.

30. Steiner B, Wooldredge J. Individual and environmental sources of work stress among prison officers. Criminal Justice and Behavior 2015; 20(10):1-19.

31. Bourbonnais R, Jauvin N, Dussault J, Vézina M. Psychosocial work environment, interpersonal violence at work and mental health among Correctional Officers. Int J Law Psychiatry 2007; 30(4):355-368.

32. Dang C, Denis C, Gahide S, Chariot P, Lefèvre T. Violence at work: forensic medical examination of police officers assaulted while on duty: comparisons with other groups of workers in two centers of the Paris area, 2010-2012. Int Arch Occup Environ Health 2016; 89(5):755-765.

33. Summerlin Z, Oehme K, Stern N, Valentine C. Disparate levels of stress in police and correctional officers: preliminary evidence from a pilot study on domestic violence. Journal of Human Behavior in the Social Environment 2010; 20(6):762-777.

34. Tsirigotis K, Gruszczynski W, Peczkowski S. Anxiety and styles of coping with occupational stress resulting from work with 'dangerous' prisioners in prison service officers. Acta Neuropsychiatr 2015; 27(5):297-306.

35. Manaus. Secretaria de Segurança Pública. Nota Técnica sobre a Rebelião no Complexo Penitenciário Anísio Jobim (Compaj). Diário Oficial do Estado de Manaus 2017; 02 jan. 
36. Garbarino S, Cuomo G, Chiorri C, Magnavita N. Association of work-related stress with mental health problems in a special police force unit. BMJ Open 2013; 3(7):e002791.

37. Tsirigotis K, Gruszczynski W, Peczkowski S. Anxiety and styles of coping with occupational stress resulting from work with 'dangerous' prisioners in prison service officers. Acta Neuropsychiatr 2015; 27(05):297-306.

38. Bierie D. The impact of prison conditions on staff well-being. International Journal of Offender Therapy and Comparative Criminology 2010; 30(65):388-397.

Artigo apresentado em 11/01/2017

Aprovado em 18/04/2017

Versão final apresentada em 08/05/2017 